\title{
Security of Equipment
}

\author{
Lesley I. Onuora \\ Astronomy Centre, University of Sussex, Falmer, Brighton BN1 9QJ, \\ U.K. e-mail: lonuora@pact.cpes.susx.ac.uk
}

\begin{abstract}
Providing adequate security for equipment is probably a problem in all parts of the world, but needs special consideration in developing countries. Social and economic conditions are very different so that implementation of advice sought from experts who are unfamiliar with local conditions can lead to disasters.

The need for adequate security must be taken into account while considering factors such as type of equipment, the site for the equipment, budgetary provisions, personnel etc.

Some examples of situations that may arise will be given in order to provoke discussion and raise the awareness of participants on this important issue.
\end{abstract}

\section{Introduction}

It is fairly obvious that when purchasing and installing equipment of any type, adequate security must be provided. This is true the world over and is not peculiar to developing countries. However the security problems involved do vary from country to country. In the context of a foreign expert being asked to give advice on the installation of equipment it is therefore possible that serious mistakes may be made. This issue of security is a rather sensitive one (since it implies that crime is expected to be committed) and is rarely, if ever, discussed at meetings such as these. However it is hoped that some thought and discussion may be provoked by this short paper which raises some of the problems that may be encountered.

\section{Siting of Equipment}

In choosing the site for an astronomical telescope, the main considerations are usually scientific e.g. for an optical telescope the quality of the seeing, the likelihood of clear skies etc. The aim is to site the telescope to obtain the best possible data. Considerations concerning adequate infrastucture and services are not usually of prime importance for a developed country. If adequate facilities are not presently available at the chosen site then provision can generally be made without any great difficulty. 
However for a developing country seeking to install a telescope the situation may be rather different. A major consideration may have to be the ability to maintain a constant power supply. Without power, the whole project will be in jeopardy, not only from the point of view of running the equipment but also from the security aspect. In many developing countries power cuts are common. This may be not just a blackout for an odd hour but could commonly be for days or weeks. Delays in making repairs are often due to lack of resources, either spare parts or money. There is very little incentive to find these resources if the location has little nearby habitation, as is likely for a site chosen purely on its astronomical merits. If the telescope is in an isolated position, lack of illumination leaves the site an open target. Therefore scientific benefits may have to be sacrificed in favour of a site closer to adequate services, such as a university campus. This may be far from ideal but would have the additional benefit of ease of monitoring and quickly dealing with any security problems.

\section{Type of Security and Budgetary Provision}

Electronic security equipment is likely to be of little use. A high wall, iron bars on windows and doors, together with armed security officers, possibly with guard dogs, are likely to be far more reliable. Thus a constant flow of funds is required to cover the drain on resources of salaries and possibly also accommodation, since it is common practice to provide on-site accommodation for security guards.

It is therefore of major importance that there be sufficient budgetary provision for any security measures to be maintained after the initial phase of the project. In many developing countries there are no formally organised research councils, or their equivalent, responsible for the funding of scientific projects. Funding may depend on the whim of whoever is in control at either the government or university level and this may change without warning. Therefore it is important to be sure of sufficient funding to pay for security arrangements over the long term before any project is undertaken. For the same reasons it is also important that the funding is not just in the form of an agreement but that it actually exists, for example in a special bank account for the project.

With sufficient funding (which is rarely available) it may be possible to partially solve the power problem by equipping the site with generators. However a constant supply of fuel and maintenance may be problems, particularly if spare parts are needed, often from abroad. The resulting delays may again expose the equipment to risk.

\section{Discussion with Local Scientists}

It is vital that the opinions of the local astronomers who will be using the equipment are sought and listened to carefully. Security will almost certainly be uppermost in the minds of the people who are involved in the project but they may be hesitant to raise the issue. One problem here is the common stereotyping that occurs between developed and developing countries. For example an astronomer from a developing country who has never travelled abroad may feel that (a) a foreign expert will be shocked that there is a likelihood that thieves will try to steal the equipment or alternatively (b) that all foreigners think that 
theft is rampant in developing countries and so mentioning security will only confirm this belief. It is very important therefore that the visitor raises the issue as a common problem that has to be solved everywhere and gives the local astronomers encouragement to express their own views.

Another aspect to be aware of is that the way the equipment is targeted may be very different. Whereas in the West computer components may be the main target, in developing countries everything is recycled, including the power cables. This is in the context of countries which have absolutely no welfare state - if a person has no livelihood there is no safety net. This breeds great ingenuity in order to survive. A visiting expert is therefore unlikely in a brief stay to understand the complexity of the security problem and must rely heavily on local advice.

\section{Access to the equipment}

One major drawback in providing tight security for the equipment is that it may become counterproductive and this needs to be borne in mind when deciding on the type of security. A very sad situation can arise where the equipment is so surrounded by security measures that its use becomes very resticted. Many of the spin-off benefits of having the telescope, such as teaching students, public education in science etc. can be lost with, at best, a few privileged people using the telescope for research and at worst no-one using it at all. A balance needs to struck between security needs, scientific productivity and outreach activities.

\section{Conclusion}

Security should be given the highest priority if a project is to be successful. However it is important to realise that there are limitations to the advice which can be offered. The success of a project may depend on giving adequate weight to local experience.

Acknowledgment. LO is a Daphne Jackson Fellow sponsored by the Royal Society.

\section{Discussion}

Rijsdijk and Kochhar were concerned that Onuora was generalizing too much from the one country with which she was most familiar. She reminded them that she had emphasized at the beginning that she could talk only from her own experience and it was not her intention to generalize. She admitted that Kochhar's story of wild elephants looking for water and breaking down the campus fencing of Kavalur Observatory illustrated a problem that she had not encountered! Osorio agreed with Onuora on the importance of involving local people. He had worked under very difficult conditions at various remote African sites. Although he had encountered problems with volcanoes, security had not been a big issue, but he had always included local people in the team. Schreuder pointed out that security lighting might contribute to light pollution. He also 
suggested that perhaps an observatory should have its own power supply. Onuora replied that generators were important but could break down and finding spare parts might be difficult. Ubachukwu remarked that building dormitories for students and living quarters for researchers is a good security measure because the continuous presence of people discourages intruders. 